\title{
Anabases
}

ANABASES Traditions et réceptions de l'Antiquité

$7 \mid 2008$

Varia

\section{Antoine HOUDAR DE LA MOTTE, L'Iliade, poème avec un Discours sur Homère}

\section{Eric Foulon}

\section{OpenEdition}

Journals

Édition électronique

URL : http://journals.openedition.org/anabases/2557

DOI : $10.4000 /$ anabases. 2557

ISSN : 2256-9421

\section{Éditeur}

E.R.A.S.M.E.

\section{Édition imprimée}

Date de publication : 1 mars 2008

Pagination : 284-286

ISSN : 1774-4296

\section{Référence électronique}

Eric Foulon, «Antoine houdar de LA motte, L'lliade, poème avec un Discours sur Homère », Anabases [En ligne], 7 | 2008, mis en ligne le 01 décembre 2011, consulté le 22 septembre 2020. URL : http:// journals.openedition.org/anabases/2557 ; DOI : https://doi.org/10.4000/anabases.2557

Ce document a été généré automatiquement le 22 septembre 2020.

(c) Anabases 


\title{
Antoine HOUDAR DE LA MOTTE, L'Iliade, poème avec un Discours sur Homère
}

\author{
Eric Foulon
}

\section{RÉFÉRENCE}

Antoine HOUDAR DE LA MOTTE, L'Iliade, poème avec un Discours sur Homère, texte établi sur l'édition originale de 1714, avec l'intégralité des illustrations et avec les variantes de l'édition de 1720, introduction et notes par Francis Assaf. Collection de Rééditions de textes du XVII ${ }^{\mathrm{e}}$ siècle publiée en supplément de la revue Littératures classiques, Société de littératures classiques, Toulouse. Diffusion Librairie Honoré Champion, Paris, 2006.

LI-278 p.

19 euros / ISBN 2-908728-47-8.

C'est une excellente initiative de la Société de Littératures Classiques que d'avoir publié L'Iliade, poème avec un Discours sur Homère d'Antoine Houdar de La Motte, dans la Collection de rééditions de textes du XVII ${ }^{\mathrm{e}}$ siècle, $\mathrm{XVII}^{\mathrm{e}}$ siècle élargi, et c'est tant mieux, car cette œuvre, en réalité, date du XVIII ${ }^{\mathrm{e}}$ siècle. On sait toute l'importance de l'Iliade de La Motte dans l'histoire littéraire française et même européenne, puisque c'est elle qui, en provoquant le courroux d'Anne Lefèvre Dacier, se trouve à l'origine de la Querelle d'Homère, dernier épisode de la Querelle des Anciens et des Modernes. Or un tel texte n'avait pas été réédité depuis le XVIII ${ }^{\mathrm{e}}$ siècle et n'était donc lisible que dans quelques bibliothèques françaises ou étrangères, disposant de fonds anciens. La Société toulousaine comble ainsi une lacune grave.

2 F. Assaf a fait précéder le texte proprement dit d'une introduction substantielle d'une cinquantaine de pages, dans laquelle il étudie la Deuxième querelle ou Querelle d'Homère, fait l'historique des rapports entretenus par Mme Dacier et La Motte avant, pendant et après, interprète l'événement d'un point de vue à la fois intellectuel, esthétique, culturel et idéologique (p. VII-XLI). Ensuite l'éditeur propose un résumé des douze livres de l'Iliade de La Motte, résumé tout à fait commode et utilisable, parce que 
procédant livre par livre et de manière non pas sommaire, mais détaillée, et il propose en outre un résumé de ce qu'il nomme «les textes périphériques ", à savoir non pas le Discours sur Homère lui-même, mais L'Ombre d'Homère, La Critique, L'Indien et le Soleil (p. XLI-XLIX). Enfin F. A. présente les principes de son édition (p. XLIX-L) et une prosopographie des auteurs des illustrations (p. L-LI).

Outre les œuvres préliminaires (Discours sur l'Iliade, L'Ombre d'Homère) et " postliminaires » (La Critique, L'Indien et le Soleil) de La Motte qui encadrent l'Iliade dans les éditions de 1714 et 1720, F. A. a eu l'excellente idée de donner deux appendices. Ce sont des échantillons de traductions d'Homère, qui sont quasiment contemporaines de l'œuvre de La Motte et qui servent de points de comparaison, sinon même de repoussoirs : il s'agit, d'une part, de l'intégralité du chant I et d'extraits des chants VI et XXIV de l'Iliade par Régnier-Desmarais et, d'autre part, du même chant I de l'Iliade par Mme Dacier.

4 Le texte de l'Iliade même est matériellement très lisible et l'on s'y repère d'autant mieux que les vers sont numérotés par l'éditeur. Les notes critiques sont rarissimes (on en dénombre 13) qui, toutes, accompagnent le Discours sur Homère. En d'autres termes, l' Iliade elle-même et les autres œuvres ne sont assorties d'aucune note. Le commentaire (ou l'annotation) reste donc à faire. La Bibliographie ou, plus modestement, les «Références bibliographiques » mêlent les auteurs classiques et les auteurs récents ou contemporains, mettent sur le même plan la littérature primaire et la littérature secondaire, ce qui est pour le moins incongru.

5 L'éditeur a le mérite de réhabiliter La Motte en montrant combien il est moderne, lui qui ne se contente pas de traduire, à l'instar de Mme Dacier, mais préfère procéder à une réécriture de l'œuvre d'Homère, non seulement en usant d'une langue et d'un style intelligibles par son lectorat et conformes à son goût, mais en introduisant des catégories psychologiques, sociales et culturelles qui touchent davantage ses contemporains. Le résultat en est une œuvre non pas burlesque, mais sérieuse, non pas mièvre, édulcorée ou défigurée, mais nouvelle, sinon novatrice, qui répond aux aspirations et aux attentes du public cultivé du siècle de Louis XIV. F. A. fait remarquer, avec subtilité, que, même si l'éloge du roi, en particulier de la part d'un académicien de tout premier plan, est un topos inévitable et obligatoire, La Motte n'a pas écrit son Iliade dans une intention encomiastique. La conclusion de l'épître liminaire laisse entendre qu'il ne saurait s'agir d'une louange du Roi-Soleil, alors à son déclin crépusculaire, mais qu'un poème à la gloire de Louis XIV reste à écrire. On ajouterait volontiers que l'image négative d'Agamemnon va dans le même sens. Avec son Iliade, l'ami de Fontenelle revendique quelque indépendance d'esprit par rapport à Homère, à la tradition, au pouvoir. L'œuvre est même empreinte d'un certain scepticisme religieux.

6 Si F. A. a opté pour le texte de 1714, dont il respecte scrupuleusement l'orthographe, la ponctuation, les retraits, reproduisant même les illustrations, en revanche, il ne justifie pas son choix, tant s'en faut, puisqu'il va jusqu'à déclarer que ce « n'est peut-être pas la toute première [édition] à sortir en 1714, mais que le libraire, sans doute sur les instances de l'auteur, a fait paraître un nouveau volume pour répondre aux critiques de Mme Dacier et de ses partisans »; et puisqu'il va jusqu'à reconnaître que l'édition de 1720 est plus soignée et que c'est justement celle qui est reprise dans les Cuvres de M. de La Motte, chez le même libraire, Grégoire Dupuis, à Paris, en 1754. Cependant il a le souci de reproduire soigneusement les corrections et autres variantes de l'édition de 
1720. Il est à supposer qu'il a préféré le texte de 1714 pour sa valeur historique, parce que c'est lui qui a fait scandale et qui est au cœur de la Querelle.

7 On aimerait faire deux remarques. $1^{\circ}$ ) Par deux fois (p. VII et en $4^{e}$ de couverture), F. A. fait naître Mme Dacier en 1654. Or, par une lettre, restée inédite et publiée en 1889, de son propre père Tanneguy Le Fèvre à Pierre-Daniel Huet, datée de Saumur, le 20 mai 1671, on sait qu'elle a alors 24 ans. Et, depuis la découverte et la publication, en 1900, de son acte de baptême, on sait qu'elle a reçu ce sacrement en l'église réformée de Preuilly-sur-Claise, le 11 août 1647. Il est donc raisonnable de considérer qu'elle est née non pas en 1654, mais sept ans plus tôt ! $2^{\circ}$ ) L'édition de l'Iliade par P. Mazon (n. 67, p. XXV) ne date pas de 1972, mais de 1937: 1972 n'est que la date d'une énième réimpression.

Le lecteur est gêné çà et là par telle ou telle difficulté : ainsi, par exemple, p. XIX, dernière ligne, il manque un «ce » devant «n'est plus Homère »; p. XXXII, 1. 18, il faut corriger « et » en « est »; p. XXXIX, 1. 27, bien que se construisant avec le subjonctif et non avec l'indicatif, il faut corriger «bien qu'il... dit » en « bien qu'il... dise »; p. XXV, l. 3 , on renonce à comprendre «Invoquant le "point d'honneur", il voit bien qu'il s'agit de plus que d'une femme ", ou, p. XLIV, 1. 18-20 : "C'est Hector qui, galvanisant à nouveau l'énergie de Pâris, décidément présenté comme un piètre guerrier, qu'Hélène ellemême commence à mépriser ", deux phrases qui ne tiennent pas debout.

Quoi qu'il en soit, il faut saluer cette entreprise si louable et former maintenant des vœux pour que voie le jour une édition de L'Iliade d'Homère, traduite en françois avec des Remarques par Anne Lefèvre Dacier, qui, en dépit de son extrême importance dans l'histoire de la littérature française et européenne, demeure toujours indisponible en 2007 !

\section{AUTEURS}

\section{ERIC FOULON}

Université Toulouse II-Le Mirail

foulon@univ-tlse2.fr 